\title{
Dynamical Analysis of Corona-virus (COVID-19) Epidemic Model by Differential Transform Method
}

\section{A. John Christopher}

Post-Graduate and Research Department of Mathematics, Government Arts College for Men, Krishnagiri 635001, Tamilnadu, India.

\section{N. Magesh ( $\nabla$ nmagi_2000@yahoo.co.in )}

Post-Graduate and Research Department of Mathematics, Government Arts College for Men, Krishnagiri 635001, Tamilnadu, India. https://orcid.org/0000-0002-0764-8390

\section{G. Tamil Preethi}

Post-Graduate and Research Department of Mathematics, Government Arts College for Men, Krishnagiri 635001, Tamilnadu, India.

\section{Research Article}

Keywords: Mathematical models, Epidemic model, Corona-virus (COVID-19), Non-linear differential equation, Differential Transform Method

Posted Date: April 29th, 2020

DOI: https://doi.org/10.21203/rs.3.rs-25819/v1

License: (c) (1) This work is licensed under a Creative Commons Attribution 4.0 International License.

Read Full License 


\title{
DYNAMICAL ANALYSIS OF CORONA-VIRUS (COVID-19) EPIDEMIC MODEL BY DIFFERENTIAL TRANSFORM METHOD
}

\author{
A. JOHN CHRISTOPHER ${ }^{1}$, N. MAGESH ${ }^{2, *}$ AND G. TAMIL PREETHI ${ }^{3}$
}

$1,2,3, *$ Post-Graduate and Research Department of Mathematics

Government Arts College for Men, Krishnagiri 635001, Tamilnadu, India.

e-mail: ${ }^{1}$ ajohnmath@gmail.com, ${ }^{2, *}$ nmagi_2000@yahoo.co.in and

${ }^{3}$ tamilpreethig@gmail.com

${ }^{2, *}$ ORCID Address : http://orcid.org/0000-0002-0764-8390.

\begin{abstract}
The aim of this paper is applying the Differential Transformation Method (DTM) to analyze and find the solution for the mathematical model described by the system of nonlinear ordinary differential equations which describe the epidemiology of the most threatening virus called Corona-virus later labelled as COVID-19. The behaviour of the outcomes is presented in terms of plots. Finally, the present study may help you to examine the wild class of real world models and also aid to predict their behaviour with respect to parameters considered in the model. The purpose of this study is to estimate the effectiveness of preventive measures, predicting future outbreaks and potential control strategies using the mathematical model.
\end{abstract}

2010 Mathematics Subject Classifications : 37M05, 34F05, 92D30.

Keywords : Mathematical models, Epidemic model, Corona-virus (COVID-19), Non-linear differential equation, Differential Transform Method (DTM).

\section{INTRODUCTION}

The new Severe Acute Respiratory Syndrome Corona-virus (SARS-CoV-2), which causes the COVID-19 disease, was first reported in December 2019 at Wuhan city, China. This new pathogen has spread rapidly around more than 200 countries. The disease was named as Corona-virus disease 2019 (COVID-19) by the World Health Organization (WHO) on 11 February 2020. Since then it killed over 9, 391 on March 19 over the infected cases of 2, 23, 082 people in more than 180 countries [31,32]. Moreover, while referring website of WHO it gives the information that globally, as of 2:00 am CEST, 27 April 2020, there have been 2, 858,635 confirmed cases of COVID-19, including 1,96, 295 deaths in more than 213 countries. As on date, there is no particular treatment, medicine or vaccine to cure infected patients completely and every day, there is always exponential increase in the death of the deceased people. More precisely, the economy of each infected country is decreased due to this cruel virus infection rate. Initially, every infected person has high fever, cough and shortness in the breath. The virus

* Corresponding Author: N. Magesh (nmagi_2000@yahoo.co.in). 
transmitted by touching the body of diseased patients to the uninfected person to his/her eyes, nose, mouth and some other parts. In order to control the spread of the virus, each country has taken almost all initializations and public health concerns are being paid globally on how many people are infected and suspected to prevent or avoid its effects on humankind. Since the start of the outbreak in Wuhan, several modeling groups around the world have reported estimations and predictions for the COVID-19 (formerly called 2019-nCov) epidemic in journal publications or on websites, one can refer [6, 9, 10, 13, 19, 20, 22, 25].

Mathematical models play an increasingly important role in our understanding of the transmission and control of infectious diseases. Epidemiological models are studied by Mathematics are constructive in comprising, proposing, planning, implementing, testing theories, prevention, evaluating a variety of detection, therapy and control programs. On the other hand, to study, examine, analyze, predict and capture the behaviour of viruses, diseases, threads and others, the mathematics is the only tool that can help us in systematics, effective and accurate manner without much expense. To detect and cure those diseases properly, we need an effective method to solve these models. For the solution of the system of linear and nonlinear differential equations, there are many methods like exact, approximate and purely numerical, stochastic models are available. Most of these are computationally intensive or need complicated symbolic computations. Generally, the exact solutions of these models are unavailable and usually are very tough.

The concept of differential transform method was first proposed by Zhou [33] in 1986 and it was applied to solve linear and non-linear initial value problems in electric circuit analysis and later it was used to solve linear and non-linear initial value problems, boundary value problems, fractional order derivative problems, fluid flow models and so on, one can refer $[1,5,12,15,21,23,24,26,27,29]$ and references therein for history and properties of DTM. Also, at the present time, this method get much attention to solve SIS (susceptible-infectedsusceptible) and SI (susceptible-infected) epidemic models [2,3], SIR (susceptible-infectedrecovered) epidemic models [16,28], influenza epidemic model [18], compartmental models [7], transmission of seasonal diseases model [4], analysis of computer virus propagation model [24], the transmission dynamical of syphilis disease model [17], SEIR (susceptible-exposed - infectedrecovered) epidemic model [14], SAEIQRS (susceptible-antidotal-exposed-infected-quarantinedrecovered-susceptible) model [8] and for HBV infection model [?,11], also one can refer the references therein for more details. To speak about the advantages and generic nature of the DTM, it is worthwhile to mention that the method can be applied to linear and nonlinear ODEs not requiring discretization, linearization or perturbation. Using DTM method, a closed form series solution or an approximate solution can be obtained. This method obtains an analytical solution in the form of a polynomial and it is possible to obtain highly accurate results or exact solutions for linear and non-linear differential equations. Another important advantage is that, this method is capable of reducing the size of computational work and still accurately provides the series solution with fast convergence rate. 
Motivated by the above useful applications of the differential transformation method, in this paper we study the solutions of the dynamics of novel corona-virus model suggested by Khan et al. [19] in the form of the system of the nonlinear differential equations and approximating the solutions in a sequence of time intervals.

\section{MATHEMATICAL FORMULATION}

The emergence and reemergence of coronavirus epidemics sparked renewed concerns from global epidemiology researchers, public health administrators and Mathematical Modeling researchers to model this. In the present investigation, we consider the compartmental mathematical model (epidemic model) has been developed by Khan and Atangana [19] for understanding the transmission of virus and presented and derived some interesting results for the projected model by comparison with some practical values (see also [9, 20, 25,30]). In this epidemic model a total number of populations $N$ at a time $t$, is divided into the following six compartments: $s(t)$ the susceptible people; $e(t)$ the exposed people; $i(t)$ the infected strength; $a(t)$ the asymptotically infected people; $r(t)$ the recovered people; $m(t)$ the reservoir. The system of nonlinear ordinary differential equations representing this epidemic model as follows:

$$
\begin{aligned}
\frac{d s}{d t} & =b-\gamma s(t)-\frac{\delta s(t)(i(t)+\beta a(t))}{N}-\varepsilon s(t) m(t) \\
\frac{d e}{d t} & =\frac{\delta s(t)(i(t)+\beta a(t))}{N}+\varepsilon s(t) m(t)-(1-\vartheta) \theta e(t)-\vartheta \alpha e(t)-\gamma e(t) \\
\frac{d i}{d t} & =(1-\vartheta) \theta e(t)-(\rho+\gamma) i(t) \\
\frac{d a}{d t} & =\vartheta \alpha e(t)-(\sigma+\gamma) a(t) \\
\frac{d r}{d t} & =\rho i(t)+\sigma a(t)-\gamma r(t) \\
\frac{d m}{d t} & =\tau i(t)+\kappa a(t)-\omega m(t)
\end{aligned}
$$

where $b$ is the rate of birth; $\gamma$ is rate of death of infected population; $\delta$ is the transmission coefficient; $\beta$ is transmissibility multiple; $\alpha$ is the transmission rate becomes infected; $\theta$ is the incubation period; $\vartheta$ is the amount of asymptomatic infection; $\varepsilon$ is the disease transmission coefficient; $\rho$ is recovery rate; $\sigma$ is asymptotically infected population; $\tau, \kappa$ is the influence of virus to $m$ by $i$ and $a$; $\omega$ is the rate of virus removing from $m$. Parameterized in equations (2.1) - (2.6) and their corresponding values are $\gamma=\frac{1}{76.79 \times 365} ; \delta=0.05 ; \beta=0.02 ; \varepsilon=0.000001231$; $\vartheta=0.1243 ; \theta=0.00047876 ; \alpha=0.005 ; \rho=0.09871 ; \sigma=0.854302 ; \tau=0.000398 ; \kappa=0.001$; and $\omega=0.01$, where the total population may vary with time $(t)$ (see for details [19]). 


\section{THE PRELIMINARIES OF DIFFERENTIAL TRANSFORMATION METHOD}

The differential transformation of the $k$ th derivative of $u(x)$ is defined by

$$
U(k)==\frac{1}{k !}\left[\frac{d^{k} u(x)}{d x^{k}}\right]_{x_{0}}
$$

from (3.1), we have

$$
u(x)=\sum_{k=0}^{\infty} U(k)\left(x-x_{0}\right)^{k}
$$

which is called inverse differential transformation of $U(k)$. In real applications, the function $u(x)$ can be expressed as a finite series and equation (3.2) can be written as

$$
u(x)=\sum_{k=0}^{n} U(k)\left(x-x_{0}\right)^{k} .
$$

Also, from (3.1) and (3.2), we have

$$
u(x)=\sum_{k=0}^{\infty}\left(x-x_{0}\right)^{k} \frac{1}{k !}\left[\frac{d^{k} u(x)}{d x^{k}}\right]_{x=x_{0}} .
$$

From (3.1) and (3.2), following properties can be obtained.

(1) If $z(x)=u(x) \pm v(x)$, then $Z(k)=U(k) \pm V(k)$.

(2) If $z(x)=\alpha u(x)$, then $Z(k)=\alpha U(k)$.

(3) If $z(x)=u^{\prime}(x)$, then $Z(k)=(k+1) U(k+1)$.

(4) If $z(x)=u^{\prime \prime}(x)$, then $Z(k)=(k+1)(k+2) U(k+2)$.

(5) If $z(x)=u^{(l)}(x)$, then $Z(k)=(k+1)(k+2) \ldots(k+l) U(k+l)$.

(6) If $z(x)=u(x) v(x)$, then $Z(k)=\sum_{l=0}^{k} U(l) V(k-l)$.

(7) If $z(x)=u_{1}(x) u_{2}(x) u_{3}(x)$, then $Z(k)=\sum_{l_{2}=0}^{k} \sum_{l_{1}=0}^{l_{2}} U_{1}\left(l_{1}\right) U_{2}\left(l_{2}-l_{1}\right) U_{3}\left(k-l_{2}\right)$.

(8) If $z(x)=\alpha x^{l}$, then $Z(k)=\alpha \delta(k-l)$, where $\delta(k-l):= \begin{cases}1 & : k=l ; \\ 0 & : k \neq l\end{cases}$

Let $S(k), E(k), I(k), A(k), R(k)$ and $M(k)$ denote the differential transformations of $s(t)$, $e(t), i(t), a(t), r(t)$ and $m(t)$ in $(2.1)-(2.6)$ respectively, where by using the fundamental operations of differential transformation method, discussed in Section 3. According to the properties of DTM recurrence relations to each equations of the system (2.1) - (2.6) as follow:

$$
\begin{aligned}
& S(k+1)=\frac{1}{k+1}\left[b \delta(k)-\gamma S(k)-\frac{\delta}{N} \sum_{l=0}^{k} S(l) I(k-l)-\frac{\delta}{N} \beta \sum_{l=0}^{k} S(l) A(k-l)\right. \\
& \left.-\varepsilon \sum_{l=0}^{k} S(l) M(k-l)\right]
\end{aligned}
$$




$$
\begin{aligned}
E(k+1)= & \frac{1}{k+1}\left[\frac{\delta}{N} \sum_{l=0}^{k} S(l) I(k-l)+\frac{\delta}{N} \beta \sum_{l=0}^{k} S(l) A(k-l)\right. \\
& \left.\quad+\varepsilon \sum_{l=0}^{k} S(l) M(k-l)-(1-\vartheta) \theta E(k)-\vartheta \alpha E(k)-\gamma E(k)\right] \\
I(k+1)= & \frac{1}{k+1}[(1-\vartheta) \theta E(k)-(\rho+\gamma) I(k)] \\
A(k+1)= & \frac{1}{k+1}[\vartheta \alpha E(k)-(\sigma+\gamma) A(k)] \\
R(k+1)= & \frac{1}{k+1}[\rho I(k)+\sigma A(k)-\gamma R(k)] \\
M(k+1)= & \frac{1}{k+1}[\tau I(k)+\kappa A(k)-\omega M(k)] .
\end{aligned}
$$

Now, we consider the initial conditions from [19] and which reduces to $S(0)=8065518$, $E(0)=200000, I(0)=282, A(0)=200, R(0)=0$ and $M(0)=50000$. Further, we take the parameter values from [19] to solve $S(k+1), E(k+1), I(k+1), A(k+1), R(k+1)$ and $M(k+1)$ in (3.5) - (3.10) up to order 8, we get, $S(k), E(k), I(k), A(k), R(k)$ and $M(k)$ respectively.

Then the closed form of the solution, where $k=8$, can be written as

$$
\begin{aligned}
& s(t)=\sum_{k=0}^{\infty} S(k) t^{k}=8065518-5151989.921 t+1648092.344 t^{2}-351983.2750 t^{3} \\
& +56467.92410 t^{4}-7258.959413 t^{5}+778.9628828 t^{6} \\
& -71.78777341 t^{7}+5.801493517 t^{8}+\cdots \\
& e(t)=\sum_{k=0}^{\infty} E(k) t^{k}=200000+380795.3031 t-271138.9061 t^{2}+87144.30619 t^{3} \\
& -18273.29759 t^{4}+2853.455652 t^{5}-355.6368747 t^{6} \\
& +36.93344854 t^{7}-3.291490540 t^{8}+\cdots \\
& i(t)=\sum_{k=0}^{\infty} I(k) t^{k}=282-106.7610111 t+115.9054943 t^{2}-64.00617349 t^{3} \\
& +19.94966931 t^{4}-4.229115184 t^{5}+0.6758131920 t^{6} \\
& -0.08655718398 t^{7}+0.009248821914 t^{8}+\cdots \\
& a(t)=\sum_{k=0}^{\infty} A(k) t^{k}=200-162.0035330 t+234.2876001 t^{2}-167.9665561 t^{3} \\
& +73.65181962 t^{4}-23.35814706 t^{5}+5.868503804 t^{6} \\
& -1.231699311 t^{7}+0.2232691825 t^{8}+\cdots
\end{aligned}
$$




$$
\begin{gathered}
+1.155646390 t^{7}-0.2159805555 t^{8}+\cdots \\
m(t)=\sum_{k=0}^{\infty} M(k) t^{k}=50000-499.6877640 t+2.396191612 t^{2}+0.08548535690 t^{3} \\
-0.04857396670 t^{4}+0.01641550553 t^{5}-0.004200914993 t^{6} \\
+0.0008827838006 t^{7}-0.0001593721135 t^{8}+\cdots
\end{gathered}
$$

\section{RESULTS AND DISCUSSION}

In this section, we evaluated the tabular values and figures obtained by DTM. Tables 1, 2, $3,4,5$ and 6 shows the solution for $s(t), e(t), i(t), a(t), r(t)$ and $m(t)$ respectively obtained by DTM and we depict the solution by for $s(t), e(t), i(t), a(t), r(t)$ and $m(t)$ in Figures 1, 2, 3, 4, 5 and 6 respectively.

\begin{tabular}{|c|c|}
\hline $\mathrm{t}$ & $\mathrm{s}(\mathrm{t})$ \\
\hline 0.1 & $7.566453523 \times 10^{6}$ \\
\hline 0.2 & $7.098315919 \times 10^{6}$ \\
\hline 0.3 & $6.659186090 \times 10^{6}$ \\
\hline 0.4 & $6.247264201 \times 10^{6}$ \\
\hline 0.5 & $5.860862253 \times 10^{6}$ \\
\hline 0.6 & $5.498397120 \times 10^{6}$ \\
\hline 0.7 & $5.158384043 \times 10^{6}$ \\
\hline 0.8 & $4.839430490 \times 10^{6}$ \\
\hline 0.9 & $4.540230458 \times 10^{6}$ \\
\hline 1.0 & $4.259559089 \times 10^{6}$ \\
\hline
\end{tabular}

Table 1. Table of susceptible population $s(t)$

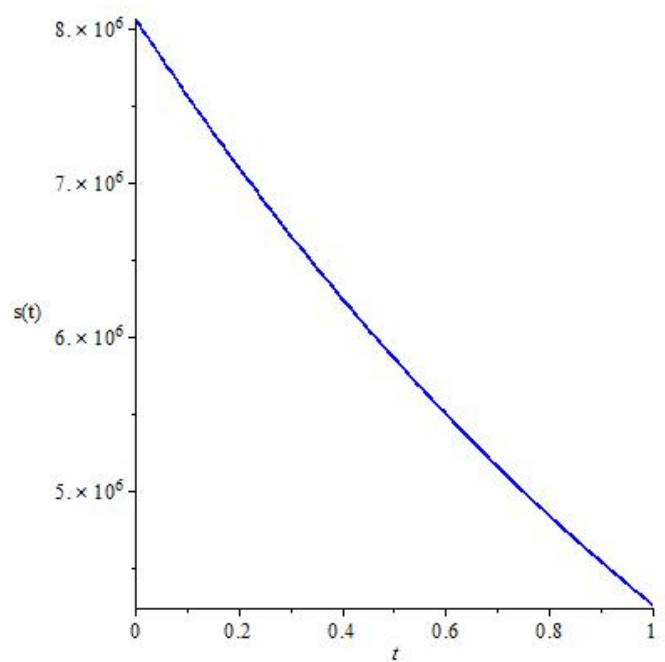

Figure 1. Numerical solutions for susceptible $s(t)$ population in a time $t$ 


\begin{tabular}{|c|c|}
\hline $\mathrm{t}$ & $\mathrm{e}(\mathrm{t})$ \\
\hline 0.1 & $2.354534863 \times 10^{5}$ \\
\hline 0.2 & $2.659823123 \times 10^{5}$ \\
\hline 0.3 & $2.920476545 \times 10^{5}$ \\
\hline 0.4 & $3.140731564 \times 10^{5}$ \\
\hline 0.5 & $3.324477716 \times 10^{5}$ \\
\hline 0.6 & $3.475283971 \times 10^{5}$ \\
\hline 0.7 & $3.596423183 \times 10^{5}$ \\
\hline 0.8 & $3.690894702 \times 10^{5}$ \\
\hline 0.9 & $3.761445329 \times 10^{5}$ \\
\hline 1.0 & $3.810588663 \times 10^{5}$ \\
\hline
\end{tabular}

Table 2. Table of exposed population $e(t)$

\begin{tabular}{|c|c|}
\hline $\mathrm{t}$ & $\mathrm{i}(\mathrm{t})$ \\
\hline 0.1 & 272.4209010 \\
\hline 0.2 & 264.8025766 \\
\hline 0.3 & 258.8268145 \\
\hline 0.4 & 254.2141174 \\
\hline 0.5 & 250.7197103 \\
\hline 0.6 & 248.1299218 \\
\hline 0.7 & 246.2589086 \\
\hline 0.8 & 244.9456943 \\
\hline 0.9 & 244.0515038 \\
\hline 1.0 & 243.4573686 \\
\hline
\end{tabular}

Table 3. Table of infected population $i(t)$

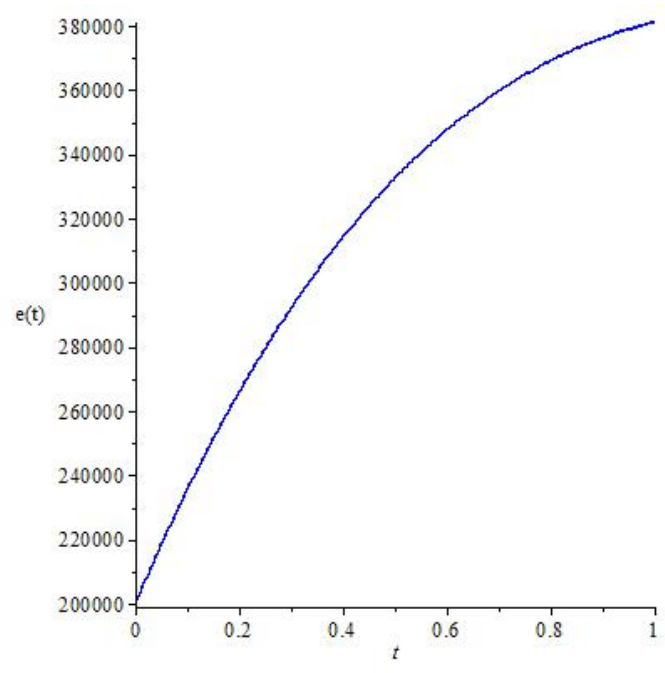

Figure 2. Numerical solutions for exposed $e(t)$ population in a time $t$

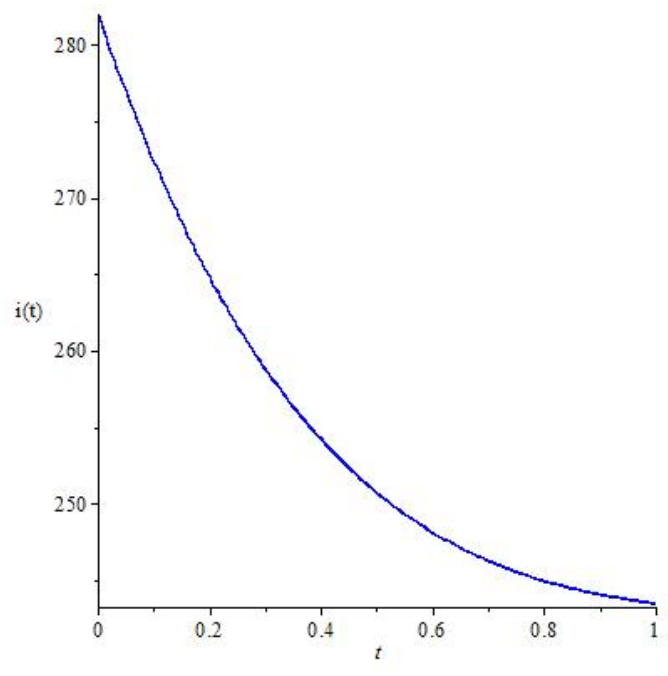

Figure 3. Numerical solutions for infected $i(t)$ population in a time $t$ 


\begin{tabular}{|c|c|}
\hline $\mathrm{t}$ & $\mathrm{a}(\mathrm{t})$ \\
\hline 0.1 & 185.9816935 \\
\hline 0.2 & 175.7377937 \\
\hline 0.3 & 168.4935698 \\
\hline 0.4 & 163.6032081 \\
\hline 0.5 & 160.5305554 \\
\hline 0.6 & 158.8326577 \\
\hline 0.7 & 158.1457792 \\
\hline 0.8 & 158.1736941 \\
\hline 0.9 & 158.6781191 \\
\hline 1.0 & 159.4712572 \\
\hline
\end{tabular}

Table 4. Table of asymptotically infected population $a(t)$

\begin{tabular}{|c|c|}
\hline $\mathrm{t}$ & $\mathrm{r}(\mathrm{t})$ \\
\hline 0.1 & 18.64246414 \\
\hline 0.2 & 35.15754814 \\
\hline 0.3 & 49.96169251 \\
\hline 0.4 & 63.38634738 \\
\hline 0.5 & 75.69293656 \\
\hline 0.6 & 87.08540133 \\
\hline 0.7 & 97.72060221 \\
\hline 0.8 & 107.7167683 \\
\hline 0.9 & 117.1600991 \\
\hline 1.0 & 126.1095334 \\
\hline
\end{tabular}

Table 5. Table of recovered population $r(t)$

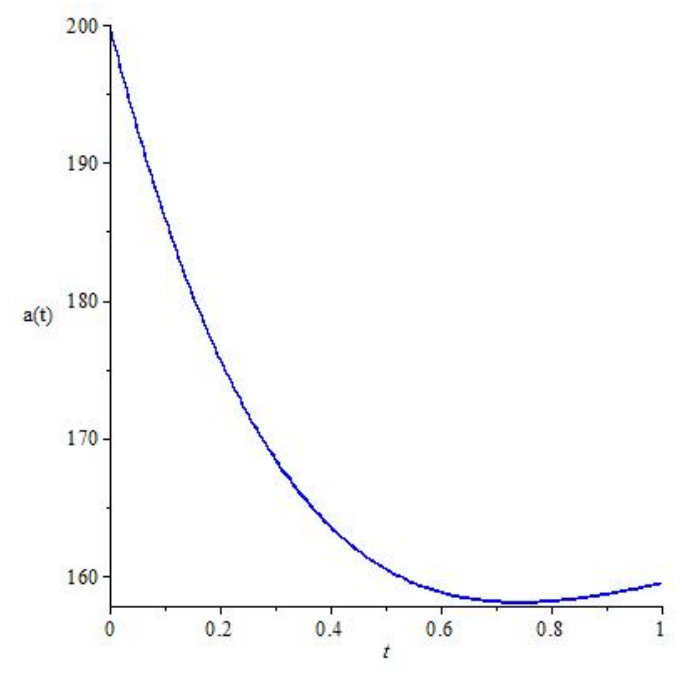

Figure 4. Numerical solutions for asymptotically infected $a(t)$ population in a time $t$

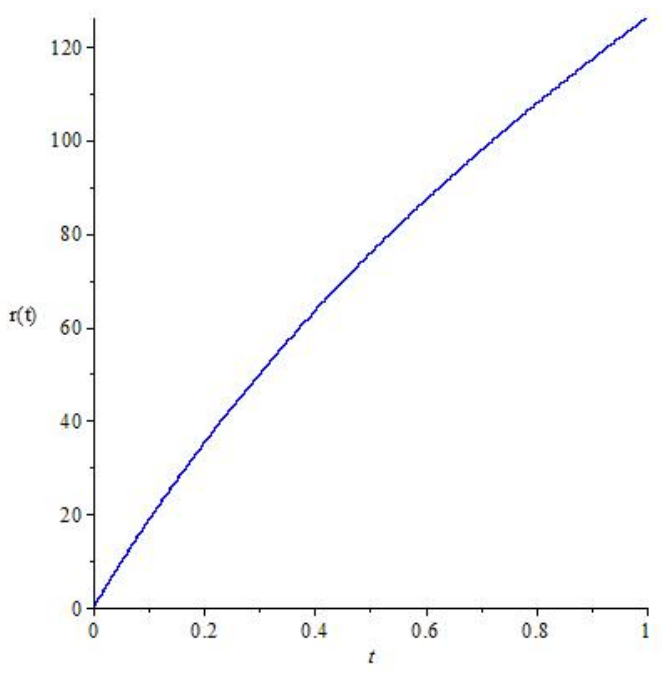

Figure 5. Numerical solutions for recovered $r(t)$ population in a time $t$ 


\begin{tabular}{|c|c|}
\hline $\mathrm{t}$ & $\mathrm{m}(\mathrm{t})$ \\
\hline 0.1 & 49950.05527 \\
\hline 0.2 & 49900.15891 \\
\hline 0.3 & 49850.31129 \\
\hline 0.4 & 49800.51266 \\
\hline 0.5 & 49750.76327 \\
\hline 0.6 & 49701.06323 \\
\hline 0.7 & 49651.41269 \\
\hline 0.8 & 49601.81166 \\
\hline 0.9 & 49552.26019 \\
\hline 1.0 & 49502.75829 \\
\hline
\end{tabular}

Table 6. Table of reservoir population $m(t)$

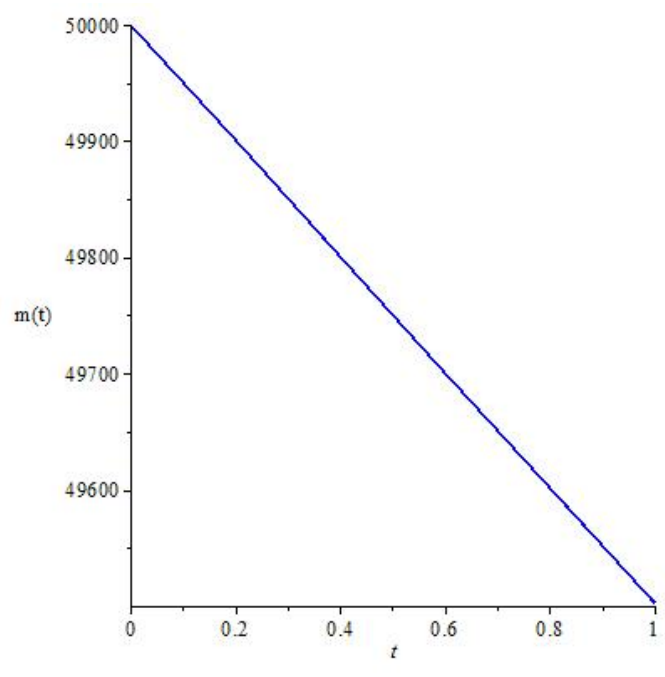

Figure 6. Numerical solutions for reservoir $m(t)$ population in a time $t$

\section{CONCLUSION}

Differential transformation method has been successfully applied to solve the dynamic model of Corona-virus (COVID-19) with given initial conditions is effectively analysed. This method provides an explicit solution which is very useful for understanding and analyzing this epidemic model based on Corona-virus. The evolution of the deadly disease and highly effective virus in the current period, where thousands and thousands of people were died till date. The obtained consequences show that, the considered method is highly well ordered and effective to analyse the real time world problems. Based on the discussion in this paper it can be concluded that the DTM is the mathematical tool, which enables one to find approximate accurate analytical solutions for epidemiological models represented by systems of nonlinear ordinary differential equations.

\section{REFERENCES}

[1] I. H. Abdel-Halim Hassan, Application to differential transformation method for solving systems of differential equations, Appl. Math. Model. 32 (2008), no. 12, 2552-2559.

[2] S. Abuasad, A. Yildirim, I. Hashim, S. A. A. Karim and J. F. G. Aguilar, Fractional multi-step differential transformed method for approximating a fractional stochastic SIS epidemic model with imperfect vaccination, Int. J. Environ. Res. Public Health, 16 (973) (2019)

[3] M. Z. Ahmad, D. Alsarayreh, A. Alsarayreh and I. Qaralleh, Differential transform method for solving SIS and SI epidemic models, Sains Malaysiana, 46(10) (2017) 2007-2017.

[4] A. J. Arenas, G. González-Parra and B. M. Chen-Charpentier, Dynamical analysis of the transmission of seasonal diseases using the differential transformation method, Math. Comput. Modelling 50 (2009), no. 5-6, 765-776.

[5] F. Ayaz, Applications of differential transform method to differential-algebraic equations, Appl. Math. Comput. 152 (2004), no. 3, 649-657. 
[6] Y. Bai, L. Yao, T. Wei, et al. , Presumed asymptomatic carrier transmission of COVID-19. Journal of the American Medical Association, (2020). https://doi.org/10.1001/jama.2020.2565.

[7] Z. Bekiryazici, M. Merdan, and T. Kesemen, Modification of the random differential transformation method and its applications to compartmental models, Communications in Statistics - Theory and Methods, (2020), 1-21. DOI: 10.1080/03610926.2020.1713372.

[8] A. K. Chakraborty, P. Shahrear, and Md. A. Islam, Analysis of epidemic model by differential transform method, J. Multidisciplinary Engg. Sci. Tech. 4 (2017), no. 2, 6574-6581.

[9] T. Chen, J. Rui, Q. Wang, Z. Zhao, J. Cui and L. Yin, A mathematical model for simulating the phasebased transmissibility of a novel Corona-virus, Infectious Diseases of Poverty (2020) 9-24.

[10] S. Choi, and M. Ki, Estimating the reproductive number and the outbreak size of COVID-19 in Korea, Epidemical Health, Volume: 42, Article ID: e2020011, (2020) 1-10, https://doi.org/10.4178/epih.e2020011.

[11] J. Danane, K. Allali and Z. Hammouch, Mathematical analysis of a fractional differential model of HBV infection with antibody immune response, Chaos Solitons Fractals 136 (2020), 109787, 1-9.

[12] Y. Do and B. Jang, Enhanced multistage differential transform method: application to the population models, Abstr. Appl. Anal. 2012, Art. ID 253890, 1-14.

[13] Editorial, The continuing 2019-nCoV epidemic threat of novel Corona-viruses to global health- The latest 2019 novel Corona-virus outbreak in Wuhan, China, International Journal of Infectious Diseases 91 (2020) 264-266.

[14] M. Farman, M. U. Saleem, A. Ahmad, M. O. Ahmad, Analysis and numerical solution of SEIR epidemic model of measles with non-integer time fractional derivatives by using Laplace Adomian decomposition method, Ain Shams Engg. J. 9 (2018) 3391-3397.

[15] Y. M. Hamada, Solution of a new model of fractional telegraph point reactor kinetics using differential transformation method, Appl. Math. Model. 78 (2020), 297-321.

[16] T. Harko, F. S. N. Lobo and M. K. Mak, Exact analytical solutions of the susceptible-infected-recovered (SIR) epidemic model and of the SIR model with equal death and birth rates, Appl. Math. Comput. 236 (2014), 184-194.

[17] M. H. Ifeyinwa, Mathematical Modeling of the transmission dynamical of syphilis disease using differential transformation method, Math. Model. Appl. 5 (2020), no. 2, 47-54.

[18] A. Jabbari, H. Kheiri and A. Bekir, Dynamical analysis of the avian-human influenza epidemic model using the semi-analytical method, Open Eng. (2015), 5, 148-156.

[19] M. A. Khan, A. Atangana, Modeling the dynamics of novel Corona-virus (2019-nCov) with fractional derivative, Alexandria Eng. J. (2020), https://doi.org/10.1016/j.aej.2020.02.033

[20] Q. Lin, S. Zhao, D. Gao, Y. Lou, S. Yang, S. S. Musa, M. H. Wang, Y. Cai, W. Wang, L. Yang and D. He, A conceptual model for the Corona-virus disease 2019 (COVID-19) outbreak in Wuhan, China with individual reaction and governmental action, International Journal of Infectious Diseases 93 (2020), 211-216.

[21] S. Owyed, M. A. Abdou, Abdel-Aty, Abdel-Haleem, W. Alharbi and R. Nekhili, Numerical and approximate solutions for coupled time fractional nonlinear evolutions equations via reduced differential transform method, Chaos Solitons Fractals 131 (2020), 109474.

[22] W. C. Roda, M. B. Varughese, D. Han and M. Y. Li, Why is it difficult to accurately predict the COVID19epidemic?, Infectious Disease Modelling 5 (2020) 271-281.

[23] A. Saravanan and N. Magesh, A comparison between the reduced differential transform method and the Adomian decomposition method for the Newell-Whitehead-Segel equation, J. Egyptian Math. Soc. 21 (2013), no. 3, 259-265. DOI: 10.1016/j.joems.2013.03.004. 25

[24] P. Shahrear, A. K. Chakraborthy, M. A. Islam and U. Habiba, Analysis of computer virus propagation based on compartmental model, Appl. Comp. Math., 7 (2018) (1-2) 12-21. 
[25] A. S. Shaikh, I. N. Shaikh and K. S. Nisar, A Mathematical model of COVID-19 using fractional derivative: Outbreak in India with dynamics of transmission and control. Preprints 2020, 2020040140 (doi: 10.20944/preprints202004.0140.v1).

[26] M. Sheikholeslami, H.R. Ashorynejad, D.D. Ganji and A. Kolahdooz, Investigation of rotating MHD viscous flow and heat transfer between stretching and porous surfaces using analytical method, Math. Probl. Eng. 2011, Art. ID 258734, 1-17.

[27] M. Sheikholeslami and D. D. Ganji, Nanofluid flow and heat transfer between parallel plates considering Brownian motion using DTM, Comput. Methods Appl. Mech. Engrg. 283 (2015), 651-663.

[28] H. M. Srivastava and H. Günerhan, Analytical and approximate solutions of fractional-order susceptibleinfected-recovered epidemic model of childhood disease, Math. Methods Appl. Sci. 42 (2019), no. 3, 935-941.

[29] M. Usman, M. Hamid, U. Khan, S. T. M. Din, M. A. Iqbal and W. Wang, Differential transform method for unsteady nanofluid flow and heat transfer, Alexandria Engineering Journal (2018) 57, 1867â̆

[30] P. Veeresha, D. G. Prakasha, N. S. Malagi, H. M. Baskonus and W. Gao, New dynamical behaviour of the Corona-virus (COVID-19) infection system with nonlocal operator from reservoirs to people, Research Square, Preprints 2020, 1-18.

[31] World Health Organization. "Coronavirus disease 2019". cited March 15, 2020. Available: https://www.who.int/health-topics/Corona-virus.

[32] World Health Organization. Coronavirus. World Health Organization, cited February 19, 2020. Available: "WHO COVID-19 situation report 29" (PDF).

[33] J. Zhou, Differential transformation and its applications for electrical circuits. Wuhan: Huazhong University Press, 1986. 
Figures

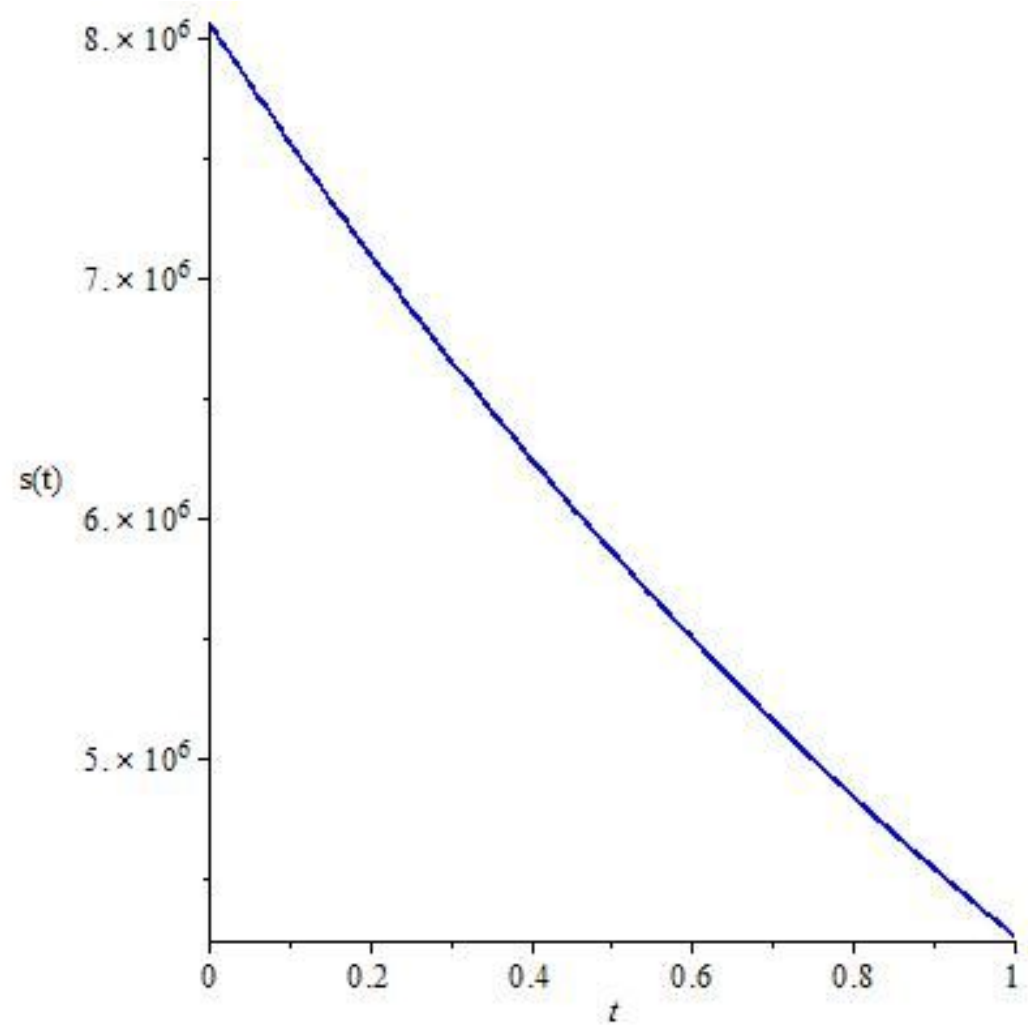

\section{Figure 1}

Numerical solutions for susceptible $\$ \mathrm{~s}(\mathrm{t}) \mathbf{S}$ population in a time $\$ \mathrm{t} \$$

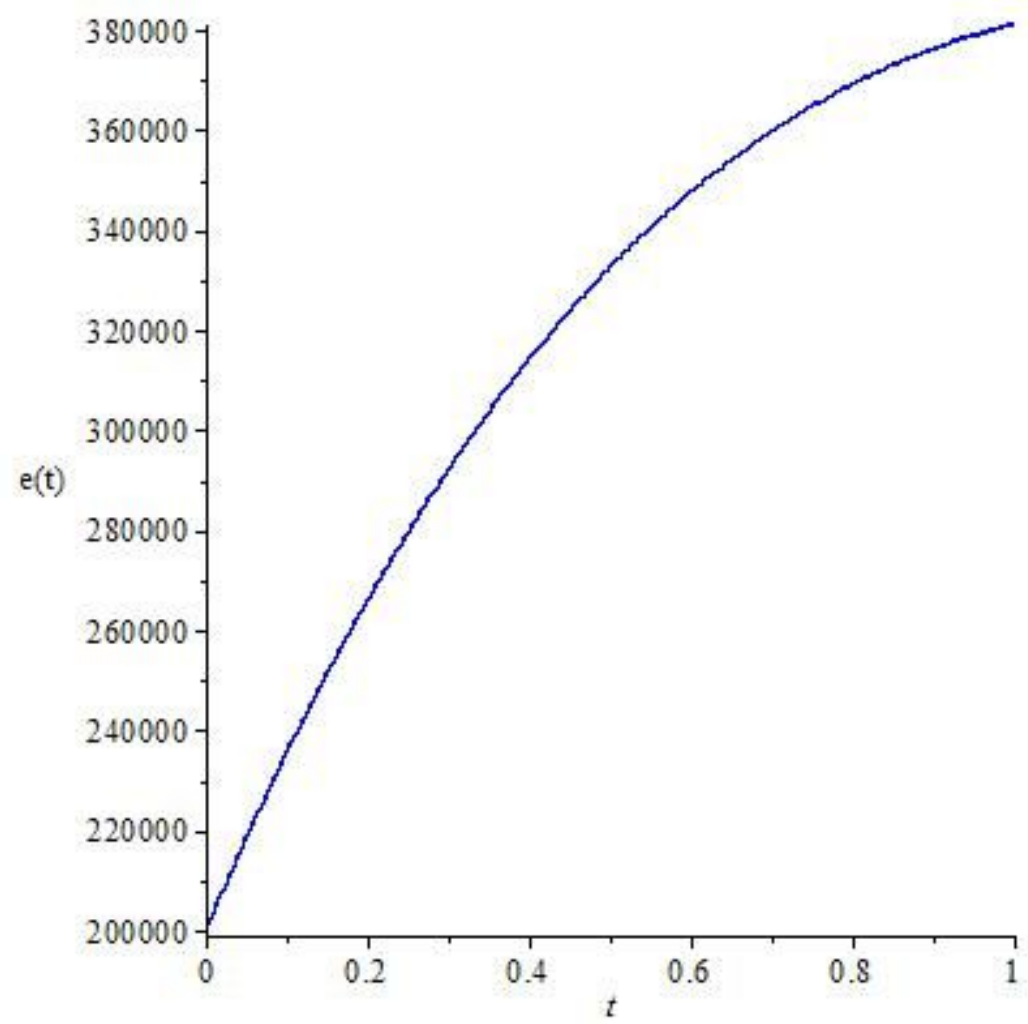


Figure 2

Numerical solutions for exposed $\$ \mathrm{e}(\mathrm{t}) \$$ population in a time $\$ \mathrm{t} \$$

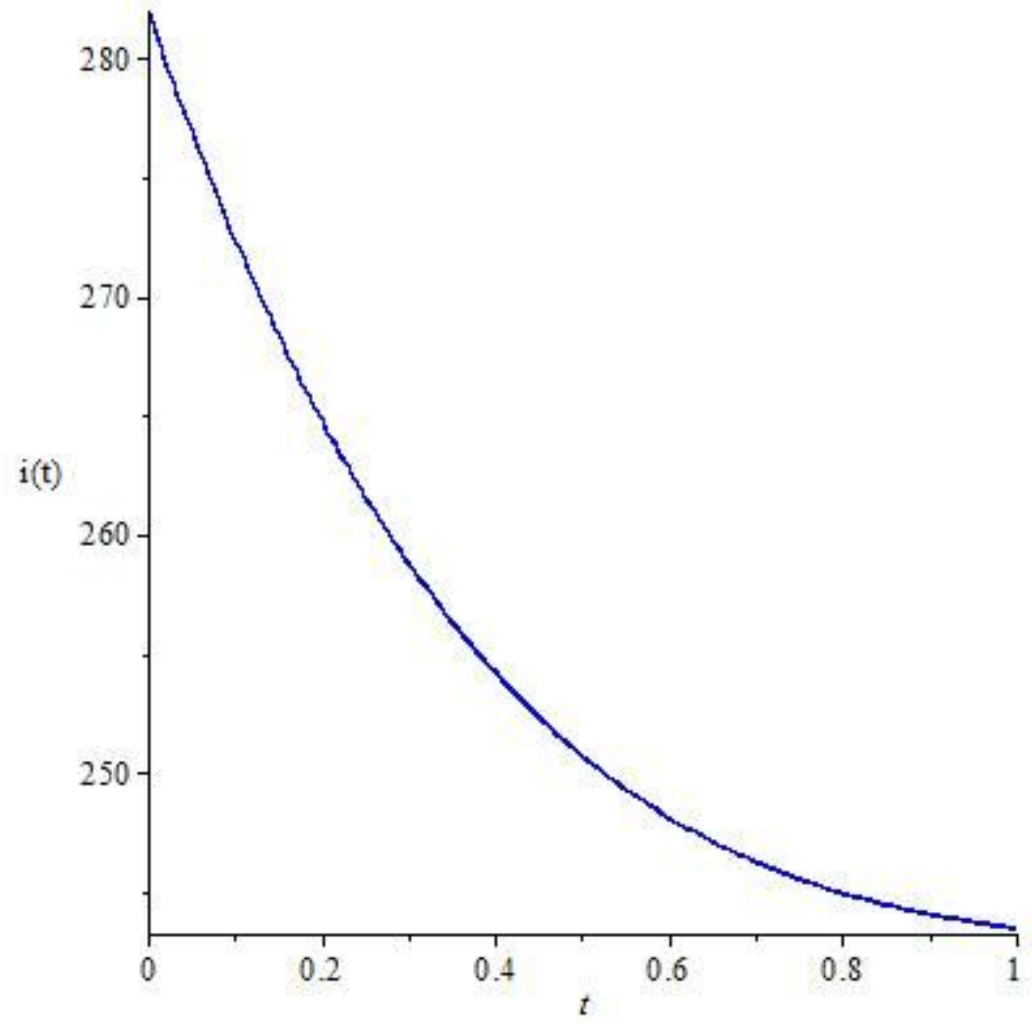

Figure 3

Numerical solutions for infected $\$ i(t) \$$ population in a time $\$$ t\$

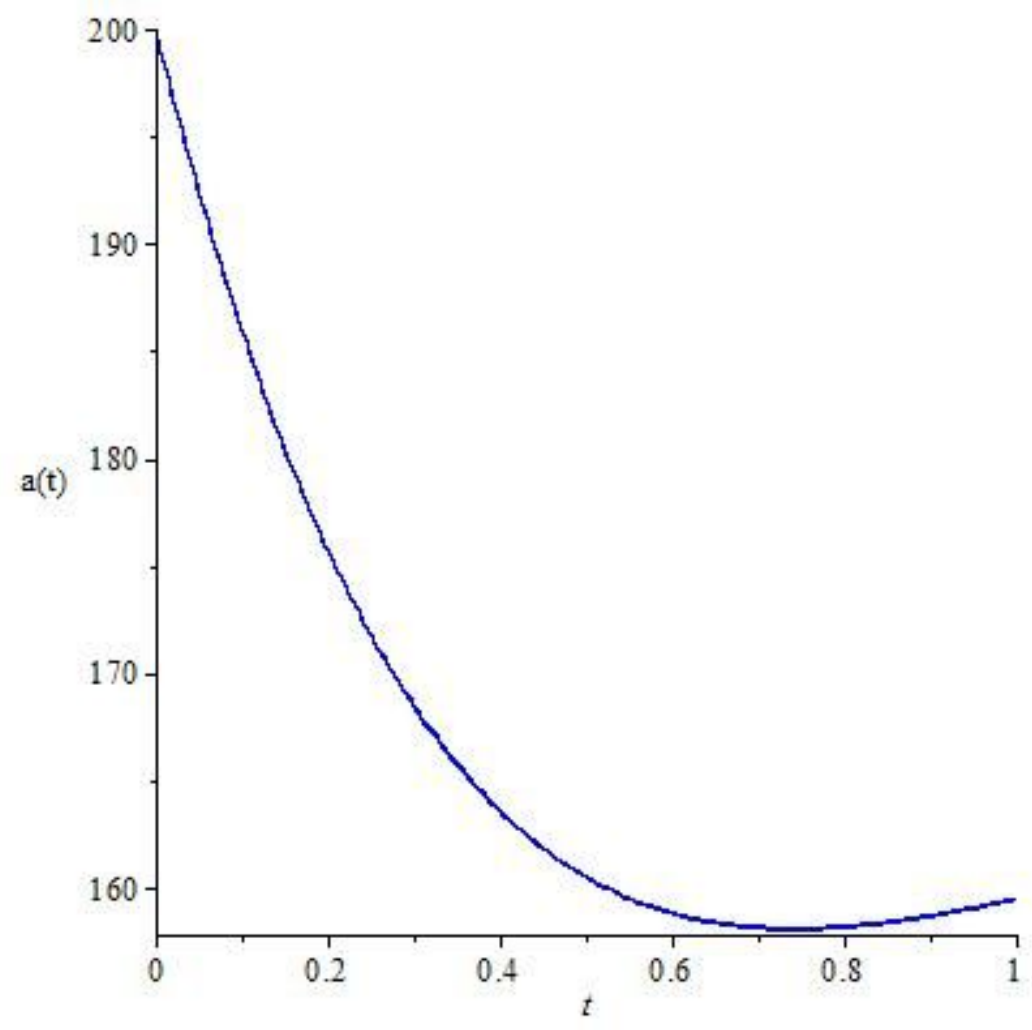


Figure 4

Numerical solutions for asymptotically infected $\$ a(t) \$$ population in a time $\$$ t $\$$

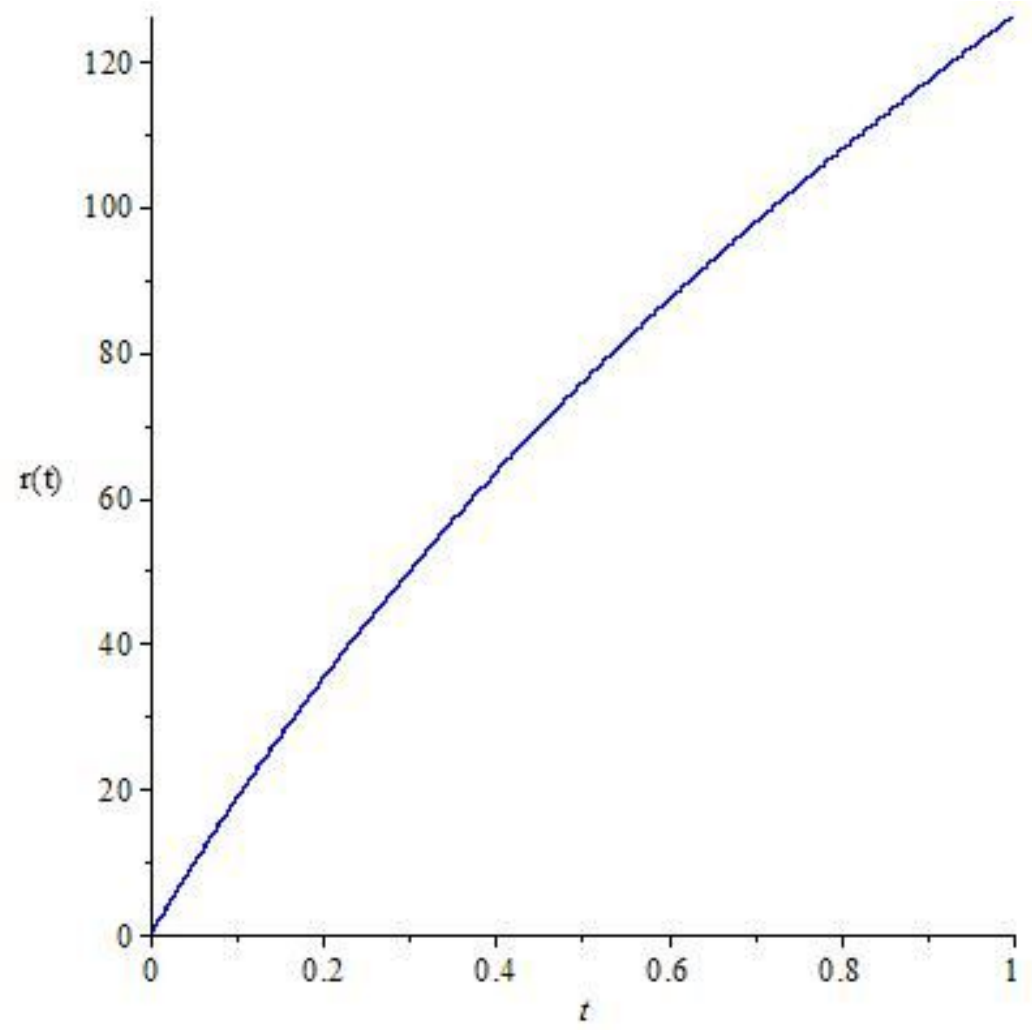

Figure 5

Numerical solutions for recovered $\$ r(t) \$$ population in a time $\$$ t\$

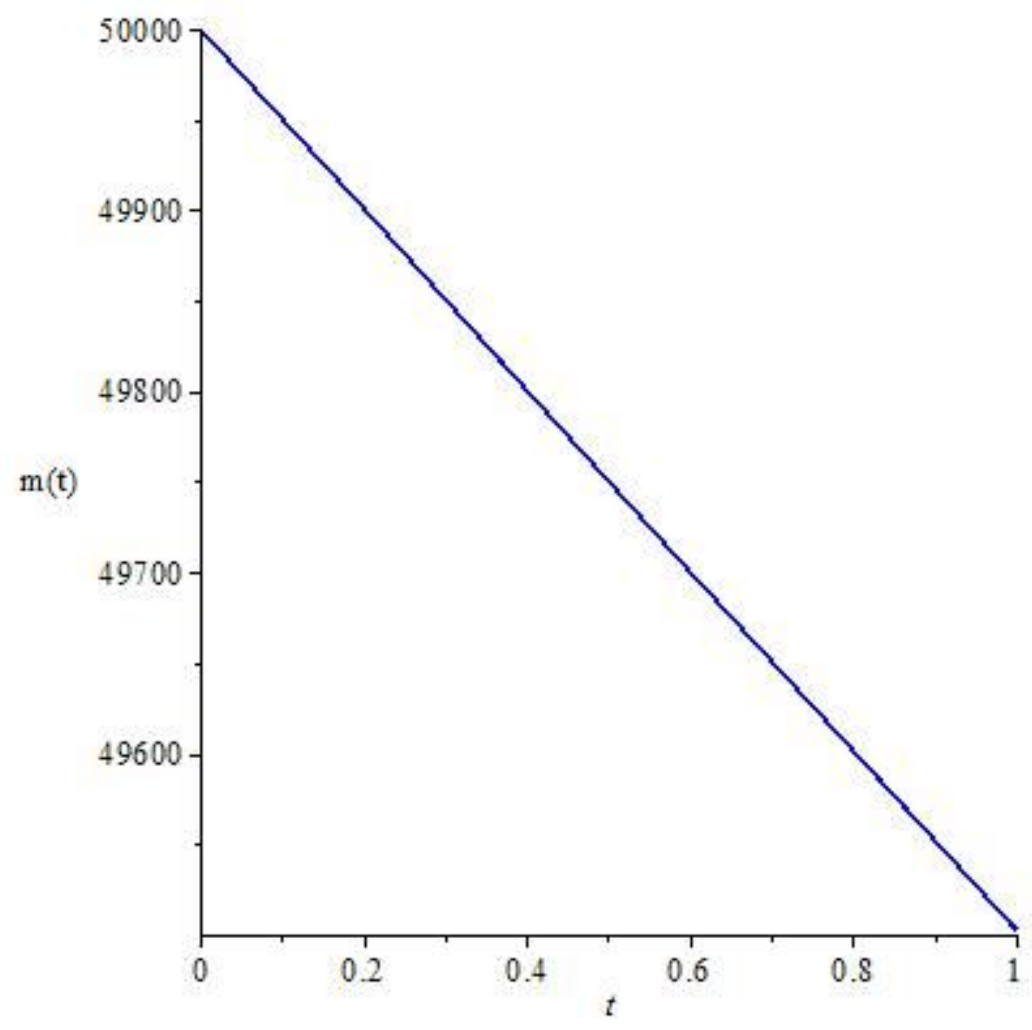


Figure 6

Numerical solutions for reservoir $\$ \mathrm{~m}(\mathrm{t}) \$$ population in a time $\$ \mathrm{t} \$$

\section{Supplementary Files}

This is a list of supplementary files associated with this preprint. Click to download.

- RV1FinalDTMCovid19AJCNMTP.tex 